\title{
Spatial self-selection in land-use-travel behavior interactions: Accounting simultaneously for attitudes and socioeconomic characteristics
}

\author{
João de Abreu e Silva ${ }^{a}$ \\ CESUR/DECivil, Instituto Superior Técnico, University of Lisbon
}

\begin{abstract}
Spatial self-selection can be ascribed to two main factors: socioeconomic characteristics or attitudinal aspects towards travel and location choices. Several studies have investigated the influence of self-selection on the relations between travel behavior and land-use patterns. So far the results could be considered mixed.

The model proposed herein uses data collected in 2009 for the Lisbon Metropolitan Area. A structural equations model was built to study the effects of spatial self-selection due to both socioeconomic and attitudinal effects. Three model specifications were considered: one treating attitudes toward travel as exogenous and two others considering them as endogenous. The preferred specification considered attitudes as exogenous. The land-use patterns are described by factors both at the residence and employment zones of each individual. The travel behavior variables included here are multidimensional and include commuting distance, car ownership, the number of trips by mode, and the total amount of time between the first and last trips. On account of the data characteristics and sample size, Bayesian estimation, as implemented in $\mathrm{AMOS}^{\mathrm{TM}}$ software, was used. The results obtained show that although the attitudinal variables significantly influence travel behavior, they do not annul the effects of land-use patterns in also contributing to shape the same behavior.
\end{abstract}

\section{Introduction}

One of the main theoretical criticisms of the use of land-use policies as a way of reducing the level of car use and changing mobility in the direction of a more intensive use of transit and nonmotorized modes is related to residential self-selection. Residential self-selection can be defined as the tendency of people to opt for residential locations based on their abilities, needs, and preferences (Mokhtarian and Cao 2008; Cao et al. 2009). This concept could be extended beyond residential to other locational choices and to other dimensions of travel behavior like car ownership, car type choice, and modal preferences (van Wee 2009). Not accounting for self-selection could result in biased model results.

Residential self-selection is related to the importance and direction of the relations between travel behavior and land-use patterns, and it is connected with the existence of causal relations between them. Here the concept of self-selection is extended to both residential and work location characteristics. Therefore, it will be referred as spatial self-selection, since it encompasses more than residential self-selection. In this paper, the impact of spatial self-selection in several travel behavior dimensions, covering both long- and short-term decisions, is studied. A preliminary analysis of the endogeneity of attitudinal effects vis-à-vis socioeconomic characteristics is made and, proceeding from that, a structural equations model (SEM) is developed. It is based on a previous model, which used the same base dataset and general structure (de Abreu e Silva, Martinez, and Goulias 2012), but excludes attitudinal variables. The base model has been extended to include self-selection related both to socioeconomic characteristics and attitudinal factors.

The remainder of the paper is organized as follows. First a literature review is offered, and then the data used is described, along with a brief description of the survey used to estimate the model developed herein. In the third section, the model conceptual structure is described, together with the travel

a joao.abreu.silva@tecnico.ulisboa.pt

Copyright 2014 João de Abreu e Silva.

Licensed under the Creative Commons Attribution - NonCommercial License 3.0. 
behavior variables used and land-use and attitudinal factors. It is followed by a section presenting a brief description of SEM and the main characteristics of the estimation procedure used, which is Bayesian estimation. Finally, a fifth section presents the model fit indicators and discusses the model results. In the conclusion, a summary and discussion of the main results are presented.

\section{Literature review}

Residential self-selection issues have recently been the object of a lot of attention in the literature relating travel behavior to land-use patterns and built environment characteristics (for recent reviews and discussions on this subject see Mokhtarian and Cao 2008; Cao et al. 2009; Bohte et al. 2009; Naess 2009; and van Wee 2009). This topic has important policy implications. If land-use patterns are simply masking the choices people make in relation to their residential location in order to pursue their desired travel behavior (Bagley and Mokhtarian 2002), then the effects of land-use policies on travel behavior will be overestimated. According to this argument, land-use patterns are endogenous to the individual and household characteristics. Naess (2009), among others (e.g., Bagley and Mokhtarian 2002), argues that, on the contrary, residential self-selection is a demonstration of the relevance of land-use patterns in influencing travel behavior, because then people would not choose different types of urban environments in order to better pursue their desired behavior. Thus, the diversity of urban environment enables individuals to self-select (Bohte et al. 2009). A number of definitions of spatial self-selection have two dimensions that are always present: one related to preferences and one related to abilities and needs (Mokhtarian and Cao 2008; Cao et al. 2009; Litman and Steele 2012). van Wee (2009) opts for a more restrictive definition, confining self-selection to mainly attitudinal issues.

According to the broader definition, spatial self-selection can be ascribed to two main factors: needs and abilities - which are correlated with socioeconomic characteristics such as income, household size, and composition — and attitudinal aspects towards travel and house location (Cao et al. 2009). These affect residential and work location in different ways. Attitudes act as pull influences, being an incentive for people to locate themselves in the places that enable their desired lifestyles. They do not influence behavior directly, but they do it through intention (Bohte et al. 2009). As a result, attitudes could be more directly linked to preferences. Socioeconomic attributes may act in a different way. They can act as restrictions (e.g., income), they can be indicators of specific preferences due to the household's specific needs (e.g., household composition or presence of children), or they can act as indicators to unobserved attitudinal variables, assuming that people with similar socioeconomic traits tend to share similar attitudinal aspects. Thus, they are more immediately linked with needs and abilities.

Here the broader definition of spatial self-selection is adopted, since land-use patterns are explicitly modeled as endogenous to both socioeconomic attributes and attitudinal variables, as shown in Figure 1.

Several studies, beginning with Kitamura et al. (1997), have investigated the influence of selfselection on the relations between travel behavior and land-use patterns. Since then, other studies have either looked specifically for the existence of spatial self-selection or at least tried to control for it. Cao et al. (2009) presents an extensive review of the impacts of residential self-selection, due to attitudinal aspects, on travel behavior. The results obtained so far could be classified as mixed. Whilst the first studies mostly have concluded that residential self-selection was more important than land-use patterns or built environment (e.g., Kitamura et al. 1997; Bagley and Mokhtarian 2002; Cao et al. 2006), other more recent ones have concluded otherwise (e.g., de Abreu e Silva, Martinez, and Goulias 2012; Schwanen and Mokhtarian 2005; Bhat and Guo 2007; Aditjandra et al. 2012; Cao et al. 2010). Cao et al. (2009) concluded, based on reviewed empirical studies, for the existence of residential self-selection, but also for the existence of non-spurious effects of land-use patterns on travel behavior. 
Ways to control for this problem include the following approaches (Bhat and Guo 2007; Mokhtarian and Cao 2008): controlling for attributes that jointly influence both travel behavior and residential location; instrumental variable methods; longitudinal methods, joint discrete choice models, and SEM, among other techniques. SEM allows for the parameterization of endogenous relations between variables, thus accounting explicitly for self-selection effects (Bagley and Mokhtarian 2002; Golob 2003b). More recent studies using simultaneous methods (e.g., SEM or joint choice models) tend to corroborate the existence of statistically significant effects on travel behavior due to land-use/built environment dimensions (Bhat and Guo 2007; Chen et al. 2008; Pinjari et al. 2007; Salon 2009; Cao et al. 2007; Scheiner and Holz-Rau 2007; Aditjandra et al. 2012). Studies using these methods, and in particular SEM, also highlight the mediating effects of several long-term decisions like car ownership (Van Acker and Witlox 2010; Chen et al. 2008; de Abreu e Silva, Martinez, and Goulias 2012) on travel decisions.

Usually the studies using SEM and dealing with spatial self-selection issues only model explicitly land-use patterns as a function of either attitudinal effects or socioeconomic characteristics as determinants of self-selection. From the studies reviewed so far, only Bagley and Mokhtarian (2002) explicitly considered attitudes as endogenous, thus allowing them to be a function of socioeconomic attributes.

Thus, including both socioeconomic and attitudinal spatial self-selection aspects within the same modeling framework and allowing attitudes to be treated as endogenous is an interesting hypothesis to be tested.

\section{Data and conceptual model}

\subsection{Data}

This study is based on an Internet survey designed to obtain data on the mobility patterns of Lisbon Metropolitan Area (LMA) residents and assess how new intermediate transport solutions (solutions that are more demand-oriented and less supply intensive) would affect current transportation choices (more details about the survey can be found in de Abreu e Silva and Martinez 2011 and de Abreu e Silva, Martinez, and Goulias 2012).

The survey was structured into four different parts: socio-demographic characterization, travel description of the previous weekday, stated preference including the new intermediate transport solutions, and attitudes toward private car and public transport use and characteristics (using Likert scales to measure the levels of agreement with a series of statements).

The survey was conducted between May and July 2009 using an invitation e-mail (with a freely accessible online version) followed by 1000 computer assisted in-person interviews with a controlled sample design (spatial distribution, gender and age of the respondent) in order to remove the bias in the observations obtained from the web-based data collection source.

In total, 2031 responses were gathered (considering respondents that reported at least their mobility behavior). From this global sample a subsample of 1099 workers was taken and used in a previous study, using the same modeling approach and a similar model structure (de Abreu e Silva, Martinez, and Goulias 2012) but excluding attitudinal variables. All the other variables used here were the same. The present study uses a subsample of 790 observations, comprising only those workers who filled out the complete survey (to allow for the construction of the attitudinal factors). The general socioeconomic and general location characteristics of these respondents were very similar to the global subsample of 1099 workers (de Abreu e Silva, Martinez, and Goulias 2012). Therefore, it is possible to conclude that there is no difference between the main socioeconomic characteristics of the workers that dropped the survey and those that completed it. 


\subsection{The SEM conceptual model}

The first research question in this model was related to the possible endogeneity between attitudes and socioeconomic characteristics. If attitudes are considered as endogenous, they should enter in the model mainly as a function of socioeconomic attributes of the respondents and their households. They could be also a function of the land-use characteristics of the residence and workplace and of the observed travel behavior, since they can be also influenced by behavior (Bohte et al. 2009). Attitudes can intervene in the process by being (Mokhtarian and Cao 2008; Cao et al. 2009):

- antecedent, meaning that they are exogenous and affect both the location of individuals and their revealed travel behavior;

- intervening, when they are influenced either by travel behavior or by the characteristics of the places where individuals are located, and therefore the relations between travel behavior and land-use patterns are mainly ones of association;

- secondary or irrelevant, having mainly association relations with travel behavior and characteristics of the places where people locate themselves.

Since the existence of spatial self-selection effects due to socioeconomic characteristics was established in earlier work (de Abreu e Silva, Martinez, and Goulias 2012), and the possibility of self-selection due to attitudinal factors was assumed in this model, three model specifications were considered regarding the endogeneity of attitudinal variables. A first specification (Model 1) considered attitudinal variables as exogenous; the second and third specifications (Model 2 and Model 3, respectively) considered attitudes as endogenous. The main difference between the latter two was that in Model 2 attitudes were only a function of socioeconomic attributes, and in Model 3 they were also a function of other endogenous variables. In order to establish the model structure, several general relations were postulated for the model, allowing other more detailed relations to be determined by the data. Generally the model considers that:

- land-use characteristics at the residence and workplace, together with socioeconomic and attitudinal factors, influence travel behavior;

- long-term decisions in travel behavior influence short-term travel decisions;

- travel behavior variables are allowed to influence land-use characteristics at the residence or work locations, thus including the feedbacks due to the information that individuals have about optimal shorter-term decisions (Domencich and McFadden 1975).

These general relations are presented in Figure 1. 
Model 1

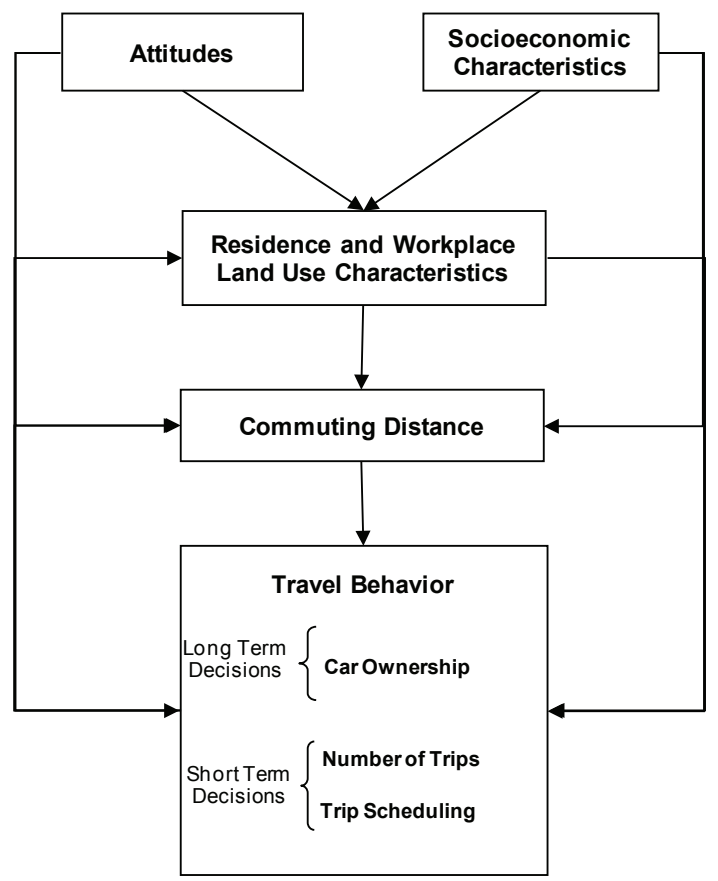

Model 3

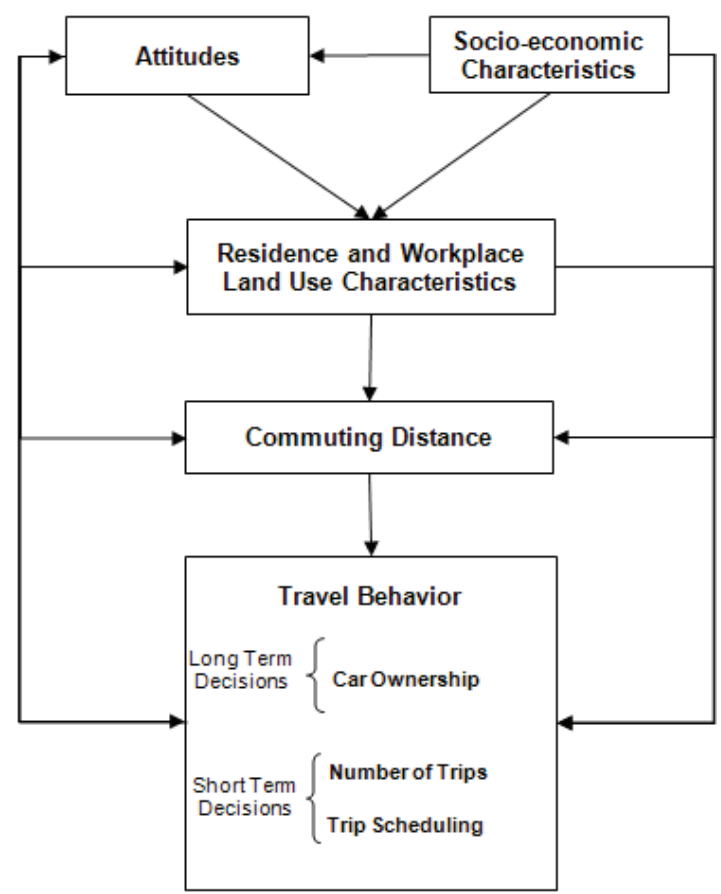

Figure 1: General structure of the competing models.
Model 2

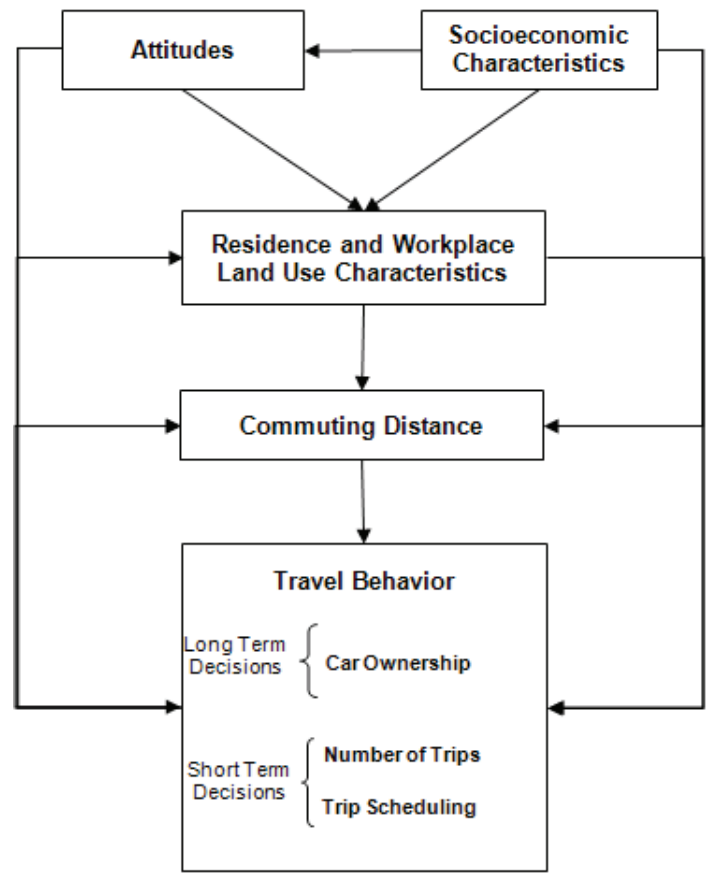


The socioeconomic variables used in the model include gender, age, household total income, household size, average age of the household, average age of the adults in the household, households with only one or two individuals, households with teenagers, and the type of working schedule.

The land-use variables were measured at the civil parish level, both for the place of residence and employment of each individual respondent (labeled as home and work, respectively). The land-use variables included a global population density (considering inhabitants, employees, and students); the mix between residents, employees, and students (ratio between employees plus students and residents); percentage of urbanized area in each civil parish; and a compactness index, which is estimated using the following formula:

$$
\operatorname{Comp}=0.28 \times \frac{P}{\sqrt{S}}
$$

where $P$ is the urban area perimeter and $S$ is the urbanized area.

The distance of each parish to Lisbon CBD was also included, and an entropy indicator was built. This entropy indicator measures the diversity balance between four different categories of land uses (residential, commerce and services, industry, and public facilities), and it was first used by Cervero, Frank, and Pivo (Kockelman 1996). It is calculated using the following formula:

$$
\text { Entropy }=-\sum_{j}^{4} \frac{\left[P_{j} \times \ln \left(P_{j}\right)\right]}{\ln (4)}
$$

where $P_{j}$ is the proportion of urban area classified in the $j^{\text {th }}$ category.

Accessibility and transport supply variables were also created. These include accessibility ratios transit/car and nonmotorized modes/car (using a gravitational approach), road supply density (km of roadways/person in each parish), the percentage of people at less than 400 meters from heavy transit stations bus stops, and the percentage of people at less than 1 kilometer from a freeway node. The accessibility ratios were estimated using the following expressions:

$$
\begin{gathered}
\frac{A c c_{i}^{\text {transit }}}{A c c_{i}^{c a r}}=\frac{\sum_{j} e^{\beta \times T_{i j}^{t}} \times O p_{j}^{t}}{\sum_{j} e^{\beta \times T_{i j}^{c}} \times O p_{j}^{c}} \\
\frac{A c c_{i}^{\text {nonmot. }}}{A c c_{i}^{\text {car }}}=\frac{\sum_{j} e^{\beta \times T_{i j}^{n m}} \times O p_{j}^{n m}}{\sum_{j} e^{\beta \times T_{i j}^{c}} \times O p_{j}^{c}}
\end{gathered}
$$

where $A c c_{i}$ is the accessibility indicator, $\beta$ is the impedance parameter calibrated based on the observed travel times, $T$ is the travel time, and $O p$ are the travel opportunities, considered here as the total number of residents, workers, and students.

All of these variables were reduced to seven factors using a factor analysis technique with principal components extraction method and orthogonal rotated correlation matrix (Varimax), characterizing both the residence and employment locations (capturing 74.2 percent of variation). The factors and their defining variables together with their scores are presented in Table 1. 
Table 1: Land-use factors and their defining factor loadings $(\mathrm{KMO}=0.78)$.

\begin{tabular}{|c|c|c|}
\hline Land-use factors & Most important variables & Loadings \\
\hline \multirow{7}{*}{$\begin{array}{c}\text { Living in central, } \\
\text { dense, and traditional } \\
\text { areas }\end{array}$} & Distance to CBD (residence) & -0.794 \\
\hline & Density (residence) & 0.816 \\
\hline & $\%$ people $400 \mathrm{~m}$ from heavy transit stations (residence) & 0.748 \\
\hline & $\%$ of urbanized land (residence) & 0.809 \\
\hline & Compacity index (residence) & -0.749 \\
\hline & Accessibility transit/Accessibility car (residence) & 0.503 \\
\hline & Capitation of roads (residence) & -0.787 \\
\hline \multirow{7}{*}{$\begin{array}{l}\text { Working in transit- } \\
\text { accessible central and } \\
\text { dense areas }\end{array}$} & Distance to CBD (work) & -0.700 \\
\hline & Density (work) & 0.717 \\
\hline & $\%$ people $400 \mathrm{~m}$ from heavy transit stations (work) & 0.622 \\
\hline & $\%$ of urbanized land (work) & 0.875 \\
\hline & Compacity index (work) & -0.812 \\
\hline & Accessibility transit/Accessibility car (work) & 0.596 \\
\hline & Capitation of roads (work) & -0.820 \\
\hline \multirow{5}{*}{$\begin{array}{l}\text { Working in mixed and } \\
\text { dense areas }\end{array}$} & Density (work) & 0.561 \\
\hline & $\%$ people $400 \mathrm{~m}$ from heavy transit stations (work) & 0.581 \\
\hline & $\%$ people $1000 \mathrm{~m}$ from freeway node (work) & -0.604 \\
\hline & Mix (work) & 0.828 \\
\hline & Entropy index (work) & 0.795 \\
\hline \multirow{2}{*}{ Living in mixed areas } & Mix (residence) & 0.935 \\
\hline & Entropy index (residence) & 0.920 \\
\hline \multirow{3}{*}{$\begin{array}{l}\text { Living in transit and } \\
\text { nonmotorized- } \\
\text { accessible areas }\end{array}$} & $\%$ people $1000 \mathrm{~m}$ from freeway node (residence) & -0.494 \\
\hline & Accessibility transit/Accessibility car (residence) & 0.717 \\
\hline & $\begin{array}{l}\text { Accessibility nonmotorized/Accessibility car (resi- } \\
\text { dence) }\end{array}$ & 0.788 \\
\hline \multirow{3}{*}{$\begin{array}{c}\text { Working in outer } \\
\text { zones not well served } \\
\text { by freeways }\end{array}$} & Distance to CBD (work) & 0.545 \\
\hline & $\%$ people $1000 \mathrm{~m}$ from freeway node (work) & -0.589 \\
\hline & Accessibility nonmotorized/Accessibility car (work) & 0.877 \\
\hline \multirow{2}{*}{ Bus supply } & $\%$ people $400 \mathrm{~m}$ from bus stops (residence) & 0.702 \\
\hline & $\%$ people $400 \mathrm{~m}$ from bus stops (work) & 0.757 \\
\hline
\end{tabular}


Attitudinal factors (Table 2) were built using a series of questions about the respondents' attitudes toward private car and public transport using Likert scales to measure their level of agreement or disagreement with the statements presented to them.

From this group of questions, and using principal components factor analysis with Varimax extraction, six attitudinal factors were extracted, explaining 61.9 percent of the total variation. Although the factors were built using Likert scales, which could be considered as ordinal, the high number of categories (seven) and the fact that they came from a single population makes it possible to find the true parameter values using factor analysis (Lubke and Muthen 2004). Muthen and Kaplan (1985), using five-category Likert scales, found that normal theory-based estimators perform well when skewness and kurtosis are moderate and the sample size is not small. Other authors (Carifio and Perla 2007; Norman 2010) also state that parametric statistics could be used with Likert scales, that the empirical evidence supports that Likert scales produce interval data, and that is appropriate to calculate Pearson correlation coefficients from Likert scales and use them in factor analysis (Carifio and Perla 2008).

Table 2: Attitudinal factors and their defining factor loadings $(\mathrm{KMO}=0.82)$.

\begin{tabular}{|c|c|c|}
\hline Attitudinal factors & Most important statements & Loadings \\
\hline \multirow{5}{*}{$\begin{array}{l}\text { Public transport } \\
\text { enthusiast }\end{array}$} & The overall public transport service is good & 0.729 \\
\hline & I can count on public transport to get anywhere on time & 0.796 \\
\hline & $\begin{array}{l}\text { Public transport offers me the flexibility I need for my } \\
\text { schedule }\end{array}$ & 0.801 \\
\hline & Public transport gets me to work quickly & 0.772 \\
\hline & $\begin{array}{l}\text { Public transport is conveniently located to most of my } \\
\text { destinations }\end{array}$ & 0.738 \\
\hline \multirow{5}{*}{ Car enthusiast } & I can count on the car to get me to my destination on time & 0.782 \\
\hline & The car offers me the flexibility I need for my schedule & 0.763 \\
\hline & The car gets me to my destination quickly & 0.810 \\
\hline & The car is comfortable & 0.520 \\
\hline & The car provides privacy and a sense of liberty & 0.566 \\
\hline \multirow{3}{*}{ Public transport critic } & Public transport is comfortable & -0.551 \\
\hline & Public transport is very crowded & 0.735 \\
\hline & The vehicles are not very clean & 0.746 \\
\hline \multirow{3}{*}{$\begin{array}{l}\text { Environmentally } \\
\text { aware }\end{array}$} & Using cars is bad for the environment & 0.677 \\
\hline & $\begin{array}{l}\text { I can get other things done while traveling with public } \\
\text { transport }\end{array}$ & 0.555 \\
\hline & Using public transport is environment friendly & 0.728 \\
\hline \multirow[t]{2}{*}{ Parking awareness } & $\begin{array}{l}\text { Difficulty in getting a parking spot near the destination is } \\
\text { the main problem of using the car }\end{array}$ & 0.820 \\
\hline & High parking cost is a major problem of using the car & 0.815 \\
\hline \multirow[b]{2}{*}{ Pricing supporter } & Parking illegally is a major offence & 0.806 \\
\hline & $\begin{array}{l}\text { People should pay more for using the car in congested } \\
\text { areas }\end{array}$ & 0.621 \\
\hline
\end{tabular}




\section{$4 \quad$ Modeling method}

The modeling method used here is structural equations modeling (SEM), which represents a combination of two types of statistical methods: factor analysis and simultaneous equations models (Kaplan 2000). In SEM, variables can be either exogenous or endogenous (Golob 2003a, 2003b). In travel behavior analysis, SEM is becoming increasingly popular as a modeling method due to its ability to estimate several endogenous variables simultaneously and also to include latent variables. In this way, it is particularly suited to modeling indirect and non-recursive relationships (in which there are feedback loops). It is also a modeling technique recommended for dealing with the issues related to this research subject (van Wee 2009; van Acker et al. 2010). Specific estimation methods in SEM allow for the use of discrete variables (e.g., number of trips by mode or car ownership levels). One of them is weighted least squares (WLS), which was developed specifically to deal with discrete and censored variables (Muthen 1984), such as some endogenous variables present in this model (number of trips by mode, number of cars in the household). The main problem with WLS has to do with its strict assumptions about sample size (Jöreskog and Sörbom 2001), usually at least 1000 observations (Golob 2003a).

Since the sample size used here contains 709 observations, a relatively new estimation method, Bayesian estimation (Byrne 2010), was used. It is implemented in the AMOS ${ }^{\mathrm{TM}}$ software (Arbuckle 2011). The Bayesian estimation method uses a prior distribution, which is combined with the observed data, using the Bayes Theorem formula to estimate an updated version for the model parameters, called a posterior distribution (Arbuckle 2011). This distribution reflects a combination of both the initial belief (given by the prior distribution) and the empirical evidence (Bolstad 2004). This is done using Markov chain Monte Carlo (MCMC) simulation techniques (Arbuckle 2011).

\section{$5 \quad$ Model results}

Table 4 presents the fit indicators obtained for the three models. The fit indicators provided by AMOS ${ }^{\mathrm{TM}}$ include the predictive posterior $\mathrm{p}$, the deviance information criteria (DIC), and the effective number of parameters.

Table 3: Model fit indicators.

\begin{tabular}{lccc}
\hline Fit indicators & $\begin{array}{c}\text { Model } \\
1\end{array}$ & $\begin{array}{c}\text { Model } \\
2\end{array}$ & $\begin{array}{c}\text { Model } \\
3\end{array}$ \\
\hline Predictive Posterior $\mathrm{p}$ & 0.46 & 0.40 & 0.30 \\
\hline DIC & 621.59 & 630.35 & 633.45 \\
\hline $\begin{array}{l}\text { Effective number of } \\
\text { parameters }\end{array}$ & 145.23 & 144.64 & 146.12 \\
\hline
\end{tabular}

The predictive posterior $\mathrm{p}$ is a Bayesian counterpart to the classic $\mathrm{p}$-value, and since it uses posterior predictive replications of the data, it is able to measure directly the discrepancy between the sample and the population quantities (Meng 1994). Thus, it can be used to test if the proposed model is either plausible or not (Lee and Song 2003). Lee and Song (2003) argue that if the predictive posterior $\mathrm{p}$ is close to 0 or 1 , then the null hypothesis, stating that the model is plausible, should be rejected. For values not far off 0.5, the model can be considered as plausible and therefore accepted (Lee 2007). The predictive posterior $\mathrm{p}$ is not adequate for comparing different models (Meng 1994; Lee 2007).

The DIC is an indicator used to compare competing models and can be viewed as a Bayesian equivalent or analogy of AIC (Spiegelhalter et al. 2002). It can be used to compare non-nested mod- 
els, but when the difference between DIC values in two models is small (less than 5) and they imply very different inferences, it could lead to misleading conclusions (Lee 2007). The effective number of parameters can be considered as the number of unconstrained parameters in the model (the process of counting is 1 if it is estimated without constraints or prior information; 0 if it is fully constrained, or the prior distribution provides all the information about the parameter; and an intermediate value if both the prior distribution and the data are informative) it represents the decrease in variance expected from the model estimation (Gelman et al. 2002).

The model outputs include the average value of the posterior (posterior mean) distribution and the posterior standard deviation, which is similar to the conventional standard error (Byrne 2010; Arbuckle 2011). Therefore, t-statistics and confidence intervals could be estimated. Actually, what is calculated is not exactly a confidence interval but a Bayesian credible interval, which has better properties than the conventional confidence interval if the posterior distribution is not normal (Arbuckle 2011).

From the results presented in Table 3, it can be concluded that Model 1 should be the preferred model, since it presents the smallest DIC. Both Model 2 and Model 3 present very similar values for this indicator. Model 1 also presents a posterior predictive $\mathrm{p}$ deemed as implying a plausible model. Accordingly, only the results of Model 1 will be presented.

The model estimation results are presented in the following way. First, the direct effects between exogenous and endogenous variables (commonly known as the matrix gamma in SEM) are presented; these are followed by the direct effects between endogenous variables (beta matrix). The total effects (sum of direct and indirect effects) between endogenous and exogenous variables and between endogenous variables are presented last. In each table, the standardized coefficient estimates (standardized posterior means) are presented with the t-statistic, estimated by dividing the posterior mean by the posterior standard deviation. Table 4 presents the direct effects due to exogenous variables. 


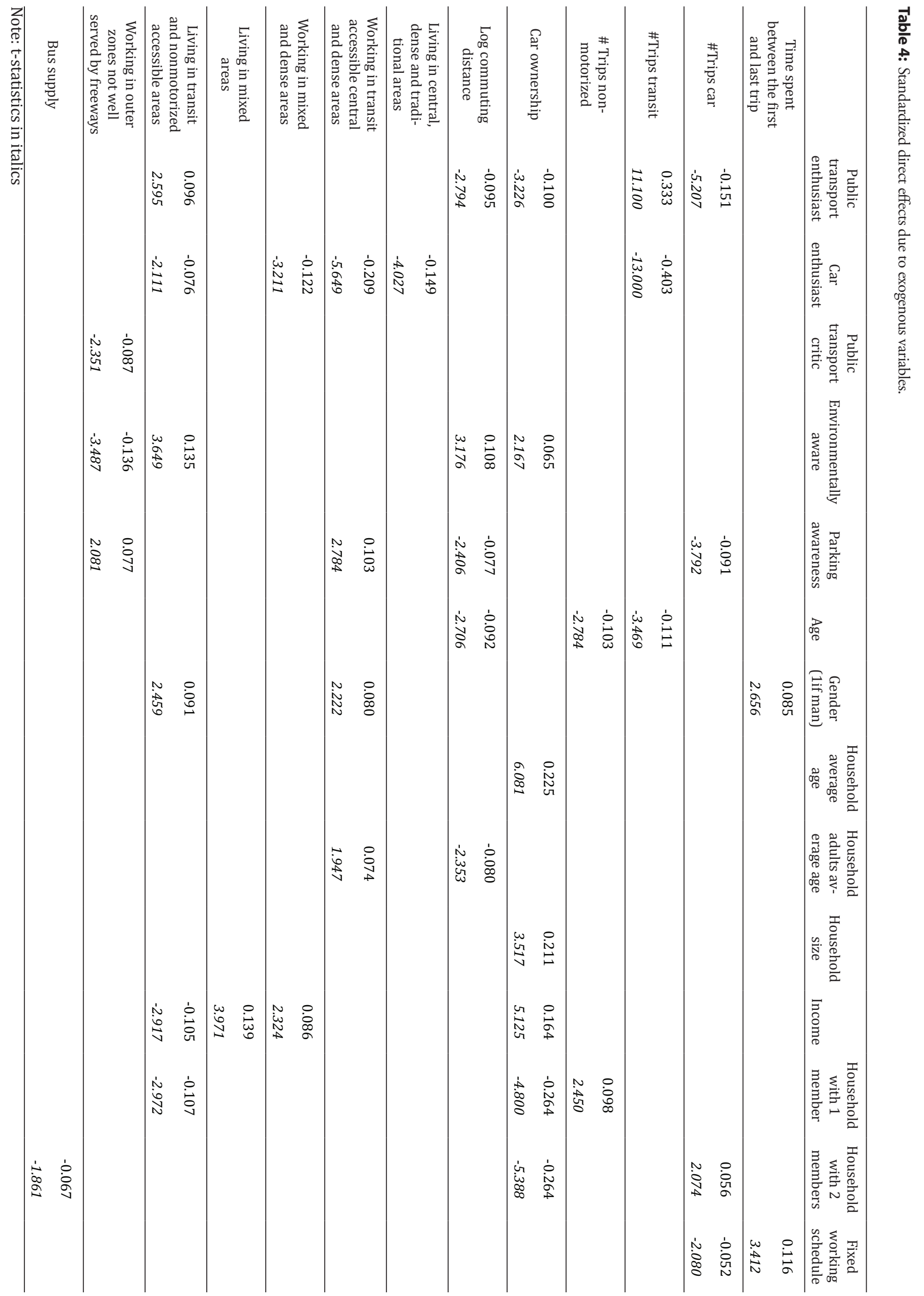


The direct effects from the exogenous variables generally show that residential and employment area characteristics are influenced by both socioeconomic factors and attitudes. These results support the affirmation that people who live and work in areas with specific characteristics tend to share similar socioeconomic characteristics and sets of common attitudes and beliefs.

Nevertheless, since they are based on cross-sectional data, these results are not the most adequate for answering the question as to the role of land-use patterns in changing beliefs and attitudes. In general, working or living in denser, mixed, central areas with good transit supply is associated with people who are not enthusiastic about the car.

Working in transit-accessible, central, and dense areas is positively affected by parking awareness, corroborating the hypothesis that these workers are aware of the difficulties in parking in their working zones, recognizing them as a deterrent for car use. Also, people who live in zones well served by transit tend to present higher loadings in the attitudinal factors public transport enthusiast and environmentally aware. People who work in outer zones not well served by freeways, which corresponds to the more rural exurbs of the LMA, are more critical of public transport and less concerned with environmental issues, but they are also more concerned about parking difficulties. These results show a good consonance between attitudes toward transportation and location patterns. What is not known is how much of this consonance is due to spatial self-selection and how much can be ascribed to the capability of the urban environment to shape and change attitudes. The comparison between the three models supports the hypothesis that attitudes are exogenous, meaning that the effects of attitudes on land use are stronger than the effects of urban configuration on attitudes. But, because the data used here is cross-sectional, this conclusion cannot be definitive. The effects of socioeconomic characteristics on location patterns are in general in accordance with what would be expected.

Looking at the travel behavior variables, commuting distance is negatively influenced by the attitudinal factors public transport enthusiast and parking awareness. It is positively influenced by the attitudinal factor environmentally aware. This means that people who commute greater distances tend to have a more negative opinion about public transport, meaning a lower level of satisfaction with transit services. People who are younger and belong to younger households tend to commute greater distances. In the last two decades, the levels of suburbanization in the LMA have increased, and-as a result of higher real estate prices in Lisbon - the percentage of suburban dwellers has included high numbers of young people. But since employment is still heavily concentrated in the center of the LMA, commuting distance is on average higher for these suburban residents.

People who own more cars tend to be more critical about public transport, but at the same time they are environmentally aware in terms of the negative impacts of car use. Their socioeconomic characteristics could be summed up as people belonging to older and bigger households with higher levels of income.

With respect to the number of trips by mode, transit trips and car trips are directly influenced by attitudinal factors. Workers who make more transit trips tend to be more enthusiastic about public transport and less so about the car. Car users, in contrast, express more negative opinions about public transport and are less aware of, or devalue, parking issues and difficulties. Workers making more transit and nonmotorized trips tend to be younger and belong to households with only one individual.

Workers who use the car more often tend to belong to households with two individuals and have a free working schedule. The time spent between the first and last trips is only directly influenced by gender (men stay longer hours away from home), but having a fixed working schedule also influences this variable positively. 
Table 5: Standardized direct effects due to endogenous variables.

\begin{tabular}{|c|c|c|c|c|c|c|c|c|c|}
\hline & $\begin{array}{l}\text { \#Trips } \\
\text { car }\end{array}$ & $\begin{array}{l}\text { \#Trips } \\
\text { transit }\end{array}$ & $\begin{array}{l}\text { \# Trips non- } \\
\text { motorized }\end{array}$ & $\begin{array}{l}\text { Log Com- } \\
\text { muting } \\
\text { distance }\end{array}$ & $\begin{array}{l}\text { Living in } \\
\text { central, } \\
\text { dense and } \\
\text { traditional } \\
\text { areas }\end{array}$ & $\begin{array}{l}\text { Working } \\
\text { in transit } \\
\text { accessible } \\
\text { central } \\
\text { and dense } \\
\text { areas }\end{array}$ & $\begin{array}{l}\text { Living } \\
\text { in mixed } \\
\text { areas }\end{array}$ & $\begin{array}{l}\text { Living in } \\
\text { transit } \\
\text { and non- } \\
\text { motorized } \\
\text { accessible } \\
\text { areas }\end{array}$ & $\begin{array}{l}\text { Working in } \\
\text { outer zones } \\
\text { not well } \\
\text { served by } \\
\text { freeways }\end{array}$ \\
\hline \multirow{2}{*}{$\begin{array}{l}\text { Time between } \\
\text { the first and } \\
\text { last trip }\end{array}$} & 0.539 & 0.406 & 0.115 & 0.085 & & & 0.081 & & \\
\hline & 11.717 & 8.120 & 3.382 & 2.297 & & & 2.314 & & \\
\hline \multirow{2}{*}{ \#Trips car } & & -0.645 & & & & & & -0.078 & \\
\hline & & -28.043 & & & & & & -3.000 & \\
\hline \multirow{2}{*}{ \#Trips transit } & & & & & & 0.076 & & & \\
\hline & & & & & & 2.303 & & & \\
\hline \multirow{2}{*}{$\begin{array}{l}\text { \# Trips non- } \\
\text { motorized }\end{array}$} & -0.080 & & & -0.141 & & & & & \\
\hline & -2.222 & & & -3.917 & & & & & \\
\hline \multirow{2}{*}{ Car ownership } & 0.116 & & & & -0.095 & & & & \\
\hline & 3.625 & & & & -3.167 & & & & \\
\hline \multirow{2}{*}{$\begin{array}{l}\text { Log commut- } \\
\text { ing distance }\end{array}$} & & & & & -0.325 & & -0.146 & 0.126 & -0.129 \\
\hline & & & & & -10.156 & & -4.710 & 3.500 & -3.686 \\
\hline $\begin{array}{l}\text { Working in } \\
\text { mixed and }\end{array}$ & -0.102 & & & & & & & & \\
\hline dense areas & -2.550 & & & & & & & & \\
\hline
\end{tabular}

Table 5 shows the existence of significant direct effects of land-use factors on travel behavior variables. It also shows evidence of competition between modes, because the number of trips made by one mode influences negatively the number of trips by other modes.

More specifically, people who live in central and more traditional areas, and also people who live in mixed areas, tend to work closer to home. Also, people who work in outer zones that are not well served by freeways tend to have a shorter commuting distance. This may be because people who work in the exurbs of the LMA tend also to live in the same exurbs. In contrast, people who live in transit-accessible areas tend to work farther away from home. This may be because the people who live in the suburbs well served by heavy transit tend to work more often in the more central areas, since the rail network is mainly radial, linking the suburbs with the LMA center.

Car ownership levels are positively influenced by the number of trips made by car and negatively by living in a central, dense, and traditional area. The first of these direct effects can, perhaps, be explained by the fact that people who pursue travel habits that involve traveling more by car might feel the need to own more cars. Thus, pursuing specific travel behavior also drives the need to own the specific means to turn the desired behavior into reality. Also, a more intense use of the car by one of the household members (the respondent) will mean that in order for other household members to also use a car, car ownership levels have to be higher.

The number of car trips also influences one land-use factor, working in mixed and dense areas, meaning that people who want to use the car less often might search for a job in this type of area. This is a clear example of a feedback derived from the information that individuals have about optimal shorter-term decisions. 
The number of nonmotorized trips is negatively influenced by the number of trips by car and by the commuting distance. People who work in transit-accessible, central, and dense areas tend to use transit more often. The number of car trips is negatively influenced by the number of transit trips, which clearly shows the existence of competition between motorized modes. Also, people who live in transitaccessible areas tend to use the car less often. This effect is also in line with the argument that these people may commute more to the central areas of the LMA, precisely the areas better served by heavy transit (mainly suburban rail and metro).

The time between the first and last trips is positively influenced by the number of trips, which is perfectly logical. It is also positively influenced by commuting distance and by living in mixed areas. 
3
0
$\vdots$
0
0
0
$\vdots$
$\vdots$
0
0

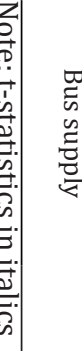

$\begin{array}{ll}\dot{\sim} & \dot{0} \\ \infty & \dot{8} \\ 0 & 0\end{array}$

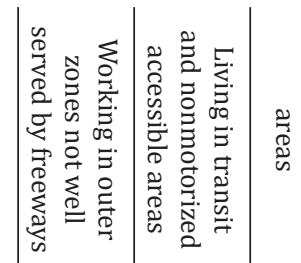

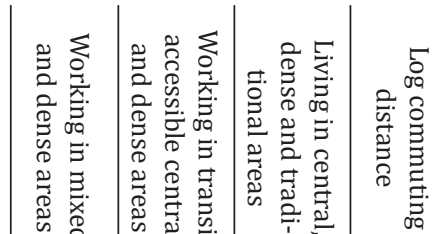

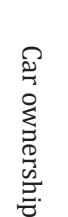

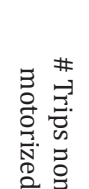

要

$\dot{\sim} \quad \dot{0}$

$\begin{array}{ll}\sim & 0 \\ \tilde{\omega}_{\omega} & \dot{\dot{\omega}} \\ \omega & \infty\end{array}$

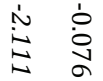

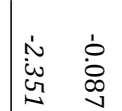

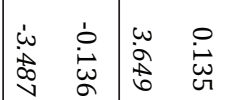

$\overrightarrow{\dot{8}} \dot{8}$

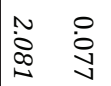

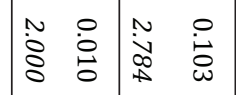

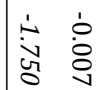

柋

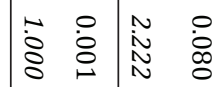

$\begin{array}{ll}r & 0 \\ \dot{\infty} & \stackrel{0}{\omega} \\ \omega & \vdots\end{array}$

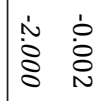

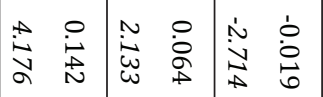

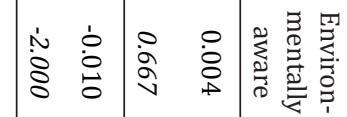

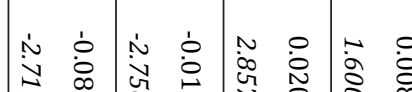

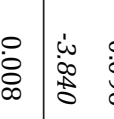

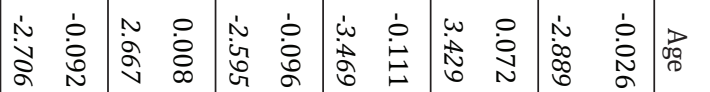

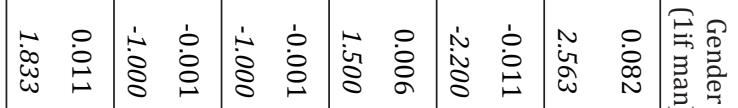

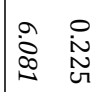

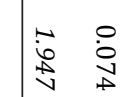

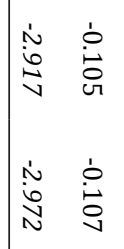

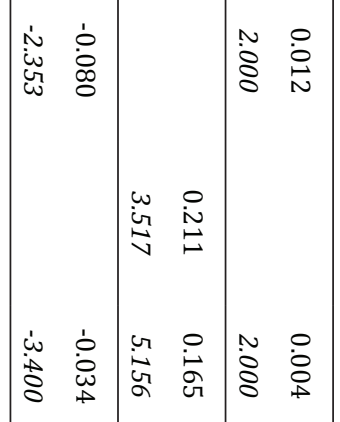

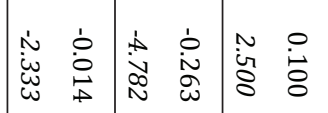

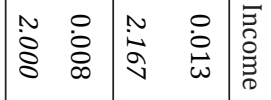

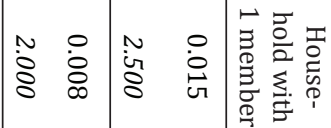

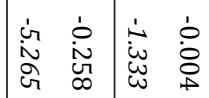

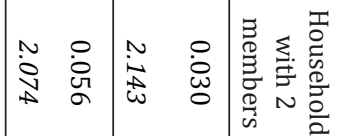

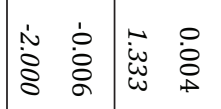

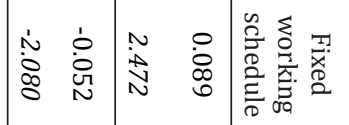


Looking at the total effects from the exogenous variables, presented in Table 6, they are generally in line with the direct effects. The total effects tend to be larger in terms of the number of exogenous variables influencing each endogenous variable due to the indirect effects passed on via other endogenous variables.

It is evident that the land-use factors characterizing the residence and working places of the respondents are influenced both by attitudinal and socioeconomic variables. With the exception of the land-use factor working in mixed and dense areas, the total effects are equal to the direct factors in all the other land-use factors.

In this land-use factor, the total effects are influenced by the fact that it is negatively affected by the number of trips by car. They include the indirect effects passed via the number of trips by car. Thus, in terms of total effects, people who are more supportive of public transport and less supportive of the car tend to work in mixed and dense areas. They are also more aware of the role of parking in car use. The total effects from the attitudinal factors are in general in agreement with what would be expected, with the exception of environmental awareness, which one would expect to have a positive effect on the number of trips using nonmotorized modes. This negative total effect is the result of indirect effects of this attitudinal factor, passed on via commuting distance and the land-use factor working in outer zones not well served by freeways (Tables 4 and 5). As stated before, since long distance commuters tend to be younger (see Table 4) and younger people usually have a stronger perception of environmental issues, these results show that although suburban commuters may be more environmentally aware, the objective conditions of their relative locations (home and work) act as a barrier to their more frequent use of nonmotorized modes. Workers who live and work in the exurbs tend to have a shorter commuting distance and are less environmentally aware, and because transit supply in these types of areas is scarce, they mainly use the car and nonmotorized modes in their daily travel. 
Table 7: Standardized total effects between endogenous variables.

\begin{tabular}{|c|c|c|c|c|c|c|c|c|c|}
\hline & $\begin{array}{l}\text { \#Trips } \\
\text { car }\end{array}$ & $\begin{array}{l}\text { \#Trips } \\
\text { transit }\end{array}$ & $\begin{array}{l}\text { \# Trips non- } \\
\text { motorized }\end{array}$ & $\begin{array}{l}\text { Log commut- } \\
\text { ing distance }\end{array}$ & $\begin{array}{l}\text { Living in } \\
\text { central, } \\
\text { dense and } \\
\text { traditional } \\
\text { areas }\end{array}$ & $\begin{array}{l}\text { Working } \\
\text { in transit } \\
\text { accessible } \\
\text { central and } \\
\text { dense areas }\end{array}$ & $\begin{array}{l}\text { Living } \\
\text { in mixed } \\
\text { areas }\end{array}$ & $\begin{array}{l}\text { Living in } \\
\text { transit } \\
\text { and non- } \\
\text { motorized } \\
\text { accessible } \\
\text { areas }\end{array}$ & $\begin{array}{l}\text { Working in } \\
\text { outer zones } \\
\text { not well } \\
\text { served by } \\
\text { freeways }\end{array}$ \\
\hline \multirow{2}{*}{$\begin{array}{l}\text { Time between } \\
\text { the first and last } \\
\text { trip }\end{array}$} & 0.530 & 0.064 & 0.115 & 0.069 & -0.022 & 0.005 & 0.071 & -0.032 & -0.009 \\
\hline & 11.277 & 1.730 & 3.382 & 1.865 & -1.833 & 1.250 & 2.029 & -2.133 & -1.500 \\
\hline \multirow{2}{*}{ \#Trips car } & & -0.645 & & & & -0.049 & & -0.078 & \\
\hline & & -28.043 & & & & -2.333 & & -3.000 & \\
\hline \multirow{2}{*}{ \#Trips transit } & & & & & & 0.076 & & & \\
\hline & & & & & & 2.303 & & & \\
\hline \multirow{2}{*}{$\begin{array}{l}\text { \# Trips non- } \\
\text { motorized }\end{array}$} & -0.080 & 0.051 & & -0.141 & 0.046 & 0.004 & 0.021 & -0.011 & 0.018 \\
\hline & -2.222 & 2.217 & & -3.917 & 3.833 & 1.333 & 3.000 & -1.375 & 2.571 \\
\hline \multirow{2}{*}{ Car ownership } & 0.116 & -0.075 & & & -0.095 & -0.006 & & -0.009 & \\
\hline & 3.625 & -3.571 & & & -3.167 & -2.000 & & -2.250 & \\
\hline \multirow{2}{*}{$\begin{array}{l}\text { Log commuting } \\
\text { distance }\end{array}$} & & & & & -0.325 & & -0.146 & 0.126 & -0.129 \\
\hline & & & & & -10.156 & & -4.710 & 3.500 & -3.686 \\
\hline \multirow{2}{*}{$\begin{array}{l}\text { Working in mixed } \\
\text { and dense areas }\end{array}$} & -0.102 & 0.066 & & & & 0.005 & & & \\
\hline & -2.550 & 2.538 & & & & 1.667 & & & \\
\hline
\end{tabular}

Note: t-statistics in italics

The total effects due to endogenous variables (Table 7) clearly show that the land-use factors significantly influence the travel behavior variables used herein. Therefore, it is possible to claim that although the model shows evidence of spatial self-selection — both due to needs and abilities associated with socioeconomic characteristics and attitudes - these do not replace the effects of land-use patterns.

Working in mixed and dense areas is positively influenced by the number of transit trips and negatively by car trips, supporting the hypothesis that people who want to travel less by car and more by transit will search for a job in areas with a high loading on this factor.

Workers who live in more traditional areas and work in more mixed areas tend to have a shorter commuting distance. The same is the case with people working in the outer exurbs of the LMA. In contrast, people living in zones with high transit accessibility tend to commute greater distances. These results are in line with both the radial structure of the suburban rail network and the stronger suburbanization of the population relative to jobs, which are still strongly concentrated in Lisbon.

The number of nonmotorized trips is negatively influenced by the number of car trips and positively by the number of transit trips (due to the effects that transit trips have on car trips). These effects show the existence of complementarities between nonmotorized modes and transit. These results show an important difference from previous models using similar model structures and data but without attitudinal variables (de Abreu e Silva, Martinez, and Goulias 2012). Here, in contrast to what was observed in previous models, the effects of longer-term decisions (such as commuting distance and car ownership) on shorter-term decisions (e.g., number of trips) are dampened and therefore do not act as the main intermediaries between land-use patterns and short-term travel behavior decisions. Since the characteristics of both samples appear to be similar, the main differences in the structure of effects can be mainly attributed to the introduced attitudinal variables. 
Although only the results of Model 1 were presented and discussed, discussion of two other relevant aspects related to the three models is pertinent. The first has to do with the total effects of landuse factors on travel behavior variables and how different they are from the ones obtained in the other two specifications. The second is the comparison between the total effects due to land-use factors and attitudinal factors, which ones are bigger, and how this relation varies along the different model specifications. The total effects due to both land-use and attitudinal factors in the three model specifications are presented in Table 8.

Table 8: Standardized total effects on travel behavior variables due to land-use patterns and attitudes.

\begin{tabular}{|c|c|c|c|c|c|c|c|c|c|c|}
\hline & $\begin{array}{l}\text { Living in } \\
\text { central, } \\
\text { dense and } \\
\text { tradition- } \\
\text { al areas }\end{array}$ & $\begin{array}{l}\text { Working } \\
\text { in transit } \\
\text { accessible } \\
\text { central } \\
\text { and dense } \\
\text { areas }\end{array}$ & $\begin{array}{l}\text { Living } \\
\text { in } \\
\text { mixed } \\
\text { areas }\end{array}$ & $\begin{array}{l}\text { Living in } \\
\text { transit } \\
\text { and non- } \\
\text { motorized } \\
\text { accessible } \\
\text { areas }\end{array}$ & $\begin{array}{l}\text { Working in } \\
\text { outer zones } \\
\text { not well } \\
\text { served by } \\
\text { freeways }\end{array}$ & $\begin{array}{c}\text { Public } \\
\text { transport } \\
\text { enthusiast }\end{array}$ & $\begin{array}{c}\text { Car } \\
\text { enthusiast }\end{array}$ & $\begin{array}{l}\text { Public } \\
\text { transport } \\
\text { critic }\end{array}$ & $\begin{array}{l}\text { Environmen- } \\
\text { tally aware }\end{array}$ & $\begin{array}{c}\text { Parking } \\
\text { awareness }\end{array}$ \\
\hline \multicolumn{11}{|c|}{ Model 1} \\
\hline \multirow{2}{*}{$\begin{array}{l}\text { Time be- } \\
\text { tween the } \\
\text { first and } \\
\text { last trip }\end{array}$} & -0.022 & 0.005 & 0.071 & -0.032 & -0.009 & -0.068 & -0.021 & 0.001 & 0.004 & -0.054 \\
\hline & -1.833 & 1.250 & 2.029 & -2.133 & -1.500 & -3.579 & -1.313 & 1.000 & 0.667 & -3.857 \\
\hline \multirow{2}{*}{ \#Trips car } & & -0.049 & & -0.078 & & -0.373 & 0.276 & & -0.010 & -0.096 \\
\hline & & -2.333 & & -3.000 & & -11.656 & 11.500 & & -2.000 & -3.840 \\
\hline \multirow{2}{*}{$\begin{array}{l}\text { \#Trips } \\
\text { transit }\end{array}$} & & 0.076 & & & & 0.333 & -0.419 & & & 0.008 \\
\hline & & 2.303 & & & & 11.100 & -13.967 & & & 1.600 \\
\hline \multirow{2}{*}{$\begin{array}{c}\text { \# Trips } \\
\text { non- } \\
\text { motorized }\end{array}$} & 0.046 & 0.004 & 0.021 & -0.011 & 0.018 & 0.041 & -0.027 & -0.002 & -0.019 & 0.020 \\
\hline & 3.833 & 1.333 & 3.000 & -1.375 & 2.571 & 2.733 & -2.455 & -2.000 & -2.714 & 2.857 \\
\hline \multirow{2}{*}{$\begin{array}{c}\text { Car } \\
\text { ownership }\end{array}$} & -0.095 & -0.006 & & -0.009 & & -0.144 & 0.046 & & 0.064 & -0.011 \\
\hline & -3.167 & -2.000 & & -2.250 & & -4.966 & 4.182 & & 2.133 & -2.750 \\
\hline \multirow{2}{*}{$\begin{array}{c}\text { Commuting } \\
\text { distance }\end{array}$} & -0.325 & & -0.146 & 0.126 & -0.129 & -0.083 & 0.039 & 0.011 & 0.142 & -0.087 \\
\hline & -10.156 & & -4.710 & 3.500 & -3.686 & -2.441 & 2.786 & 1.833 & 4.176 & -2.719 \\
\hline \multicolumn{11}{|c|}{ Model 2} \\
\hline \multirow{2}{*}{$\begin{array}{c}\text { Time } \\
\text { between } \\
\text { the first } \\
\text { and last } \\
\text { trip }\end{array}$} & -0.023 & 0.005 & 0.071 & -0.031 & -0.009 & -0.068 & -0.023 & 0.001 & 0.005 & -0.054 \\
\hline & -1.917 & 1.250 & 2.152 & -2.067 & -1.800 & -3.579 & -1.438 & 1.000 & 0.833 & -3.857 \\
\hline \multirow{2}{*}{ \#Trips car } & & -0.049 & & -0.075 & & -0.376 & 0.278 & & -0.010 & -0.096 \\
\hline & & -2.450 & & -2.778 & & -12.533 & 12.636 & & -2.000 & -4.000 \\
\hline \multirow{2}{*}{$\begin{array}{l}\text { \#Trips } \\
\text { transit }\end{array}$} & & 0.076 & & & & 0.336 & -0.422 & & & 0.008 \\
\hline & & 2.452 & & & & 11.200 & -14.067 & & & 2.000 \\
\hline \multirow{2}{*}{$\begin{array}{c}\text { \# Trips } \\
\text { non- } \\
\text { motorized }\end{array}$} & 0.045 & 0.004 & 0.021 & -0.012 & 0.018 & 0.041 & -0.027 & -0.002 & -0.019 & 0.019 \\
\hline & 3.750 & 2.000 & 3.000 & -1.500 & 2.571 & 2.929 & -2.700 & -2.000 & -2.375 & 2.714 \\
\hline \multirow{2}{*}{$\begin{array}{c}\text { Car } \\
\text { ownership }\end{array}$} & -0.097 & -0.006 & & -0.009 & & -0.146 & 0.047 & & 0.060 & -0.011 \\
\hline & -3.464 & -2.000 & & -2.250 & & -4.867 & 3.917 & & 2.069 & -2.750 \\
\hline \multirow{2}{*}{$\begin{array}{c}\text { Commuting } \\
\text { distance }\end{array}$} & -0.323 & & -0.147 & 0.127 & -0.126 & -0.083 & 0.037 & 0.011 & 0.144 & -0.086 \\
\hline & -10.419 & & -4.324 & 3.735 & -3.818 & -2.441 & 2.846 & 1.833 & 4.235 & -2.529 \\
\hline
\end{tabular}




\begin{tabular}{|c|c|c|c|c|c|c|c|c|c|}
\hline \multicolumn{10}{|c|}{ Model 3} \\
\hline Time & -0.023 & 0.004 & 0.069 & -0.032 & -0.009 & -0.070 & -0.020 & 0.005 & -0.054 \\
\hline trip & -2.091 & 0.571 & 2.029 & -2.286 & -1.800 & -3.333 & -1.250 & 0.833 & -3.600 \\
\hline \multirow{2}{*}{ \#Trips car } & & -0.114 & & -0.077 & & -0.375 & 0.266 & -0.010 & -0.090 \\
\hline & & -4.750 & & -2.962 & & -11.364 & 11.565 & -2.500 & -3.462 \\
\hline \multirow{2}{*}{$\begin{array}{l}\text { \#Trips } \\
\text { transit }\end{array}$} & & 0.161 & & & & 0.335 & -0.403 & & \\
\hline & & 4.472 & & & & 11.167 & -13.897 & & \\
\hline \multirow{2}{*}{$\begin{array}{c}\text { \# Trips } \\
\text { non- } \\
\text { motorized }\end{array}$} & 0.047 & 0.011 & 0.021 & -0.013 & 0.019 & 0.040 & -0.026 & -0.020 & 0.019 \\
\hline & 3.615 & 2.200 & 3.000 & -1.857 & 2.714 & 2.667 & -2.600 & -2.857 & 2.714 \\
\hline \multirow{2}{*}{$\begin{array}{c}\text { Car } \\
\text { ownership }\end{array}$} & -0.097 & -0.016 & & -0.009 & & -0.147 & 0.045 & 0.067 & -0.010 \\
\hline & -3.345 & -3.200 & & -2.250 & & -4.742 & 4.500 & 2.161 & -2.500 \\
\hline \multirow{2}{*}{$\begin{array}{l}\text { Commuting } \\
\text { distance }\end{array}$} & -0.325 & -0.016 & -0.145 & 0.126 & -0.130 & -0.084 & 0.038 & 0.143 & -0.083 \\
\hline & -9.848 & -2.667 & -4.677 & 3.938 & -4.194 & -2.545 & 2.923 & 4.086 & -2.594 \\
\hline
\end{tabular}

The aspects that stand out from Table 8 are:

- the total effects due to land-use factors are quite similar between Model 1 and Model 2. The differences in the standardized coefficients are small and significance levels are similar;

- Model 3 exhibits some relevant differences in the total effects due to land-use factor working in transit accessible central and dense areas. They tend to present higher values than the ones observed in the first two model specifications. The total effects from all the other land-use factors are similar;

- the total effects from attitudinal factors tend to be similar in all model specifications, particularly those due to the first two factors;

- the main exception are the effects due to public transport critic, which are absent in Model 3;

- generally speaking, the attitudinal factors tend to have stronger impacts than land-use factors, corroborating the conclusions of Aditjandra et al. (2012). But there are two relevant exceptions - the number of trips by nonmotorized modes and commuting distance, where land-use factors have greater influence.

The main conclusion that can be drawn from these results is that these different specifications don't lead to very different conclusions in terms of the total effects of land-use patterns on travel behavior, particularly when attitudes are considered as endogenous to socioeconomic attributes. When attitudes are considered as endogenous to location characteristics, there are more important changes, but they are far from being sufficient to alter substantially the conclusions drawn from Model 1.

\section{Conclusions}

The results obtained show that even when spatial self-selection due to both abilities and needs associated with socioeconomic and attitudinal effects is considered, land-use patterns significantly affect travel behavior. Attitudinal factors regarding transport modes do play a role in explaining the characteristics of the work and residential locations. They also contribute to explaining travel behavior in a generally intuitive way. The results also show that, for several travel behavior variables, attitudinal factors tend to have a stronger influence than land-use patterns. As expected for commuting distance and trips using nonmotorized modes, the role of land use is stronger. Although nonmotorized modes are very sensitive 
to distance and commuting distance is dependent on the urban structure, the fact that the attitudinal questions used to build these factors didn't include aspects related to the use of these modes - nor attitudes related to locations, characteristics, and urban environment-may also contribute to these results. Nevertheless, transport-related attitudes do significantly influence the choice of different types of urban environment both at the residence and the employment levels.

It is also important to point out that these results are in line with the conclusions drawn from other recent studies that analyzed the effects of residential self-selection due to attitudes and lifestyles (see Cao et al. 2009).

Finally, at least for the dataset used here (which is cross-sectional and doesn't have a temporal dimension), considering attitudes as either endogenous or exogenous doesn't have a significant effect on the conclusions drawn. Studying the endogeneity of attitudes vis-à-vis urban environment and the causality relations that can arise between them is an arduous but very relevant research direction with the potential to disentangle the issues related to self-selection.

\section{$7 \quad$ Acknowledgments}

The author would like to thank the MIT Portugal Program - Transportation Systems for providing the data used here. The comments of two anonymous referees to whom the author is grateful helped to improve this paper substantially.

\section{References}

Aditjandra, P.T., X. Cao, and C. Mulley. 2012. Understanding neighbourhood design impact on travel behavior: An application of structural equations model to a British metropolitan data. Transportation Research A 46: 22-32. doi: 10.1016/j.tra.2011.09.001.

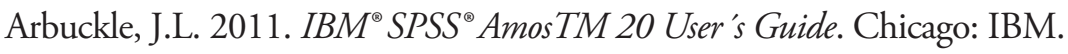

Bagley, M.N. and P. Mokhtarian. 2002. The impact of residential neighborhood type on travel behavior: A structural equations modeling approach. The Annals of Regional Science 36: 279-297. doi: $10.1007 / \mathrm{s} 001680200083$.

Bhat, C. and J.Y. Guo. 2007. A comprehensive analysis of built environment characteristics on household residential choice and auto ownership levels. Transportation Research Part B 41: 506-526. doi: 10.1016/j.trb.2005.12.005.

Bohte, W., K. Maat and B. van Wee. 2009. Measuring attitudes in research on residential self-selection and travel behaviour: A review of theories and empirical research. Transport Reviews 29(3): 325-357. doi:10.1080/01441640902808441.

Bolstad, W.M. 2004. Introduction to Bayesian Statistics. Hoboken: Wiley.

Byrne, B. 2010. Structural Equation Modeling with AMOS. Basic Concepts, Applications, and Programming. Second Edition. New York: Routledge.

Cao, X., P.L. Mokhtarian, and S.L. Handy. 2006. The impacts of the built environment and residential self-selection on nonwork travel: a seemingly unrelated regression approach. Presented at the 85 th Transportation Research Board Annual Meeting, Washington, DC, January 22-26, 2006.

2007. Do changes in neighborhood characteristics lead to changes in travel behavior? A structural equations modeling approach. Transportation 34(5): 535-556. doi: 10.1007/s11116-0079132-x. 
- 2009. Examining the impacts of residential self-selection on travel behaviour: A focus on empirical findings. Transport Reviews 29 (3): 359-395. doi: 10.1080/01441640802539195.

Cao, Xinyu, Z. Xu, and Y. Fan. 2010. Exploring the connections among residential location, self-selection, and driving: Propensity score matching with multiple treatments. Transportation Research Part A 44: 797-805. doi: 10.1016/j.tra.2010.07.010.

Carifio, J. and R. Perla. 2007. Ten common misunderstandings, misconceptions, persistent myths and urban legends about Likert scales and Likert response formats and their antidotes. Journal of Social Sciences 2: 106-116. doi: 10.3844/jssp.2007.106.116

- 2008. Resolving the 50 year debate around using and misusing Likert scales. Medical Education 42: 1150-1152. doi: 10.1111/j.1365-2923.2008.03172.x

Chen, C., H. Gong, and R. Paaswell. 2008. Role of the built environment on mode choice decisions: additional evidence on the impact of density. Transportation 35: 285-299. doi: 10.1007/s11116007-9153-5

de Abreu e Silva, J., L. Martinez, and K. Goulias. 2012. Using a multi equation model to unravel the influence of land use patterns on travel behavior of workers in Lisbon. Transportation Letters 4(4): 193-209. doi:10.3328/TL.2012.04.04.193-209

de Abreu e Silva, J. and L. Martinez. 2011. The application of Internet based surveys in the Lisbon Metropolitan Area. Presented at the 9th International Conference on Transport Survey Methods, Termas de Puyheue, Chile, November 11-18, 2011.

Domencich, T.A. and D. McFadden. 1975. Urban Travel Demand. A behavioral analysis. Amsterdam: North-Holland.

Gelman, A., X. Meng, and H. Stern. 1996. Posterior predictive assessment of model fitness via realized discrepancies. Statistica Sinica 6: 733-807. doi: 10.1.1.142.9951

Golob T.F. 2003a. Structural equations modeling for travel behavior research, Transportation Research, Part B 37(1): 1-25. doi: 10.1016/S0191-2615(01)00046-7

- 2003b. Structural equation modeling. In Transportation Systems Planning. Methods and Applications, edited by K.G. Goulias. Boca Raton: CRC Press.

Jöreskog, K. and D. Sörbom. 2001. LISREL ${ }^{\circledR}$ 8: User's Reference Guide. Lincolnwood: SSI Scientific Software International.

Kaplan, D. 2000. Structural Equation Modeling. Foundations and Extensions. Thousand Oaks: Sage Publications.

Kitamura, R., P.L. Mokhtarian, and L. Laidet. 1997. A micro-analysis of land use and travel in five neighborhoods in the San Francisco Bay Area. Transportation 24: 125-158. doi: 10.1023/A:1017959825565

Kockelman, K.M. 1996. Travel behavior as a function of accessibility, land use mixing, and land use balance: Evidence from the San Francisco Bay Area. University of California, Berkeley, Master Thesis, www.ce.utexas.edu.

Lee, S. 2007. Structural Equation Modeling. A Bayesian Approach. Chichester: Wiley.

Lee, S. and X. Song. 2003. Bayesian analysis of structural equation models with dichotomous variables. Statistics in Medicine 22: 3073-3088. doi: 10.1207/s15327906mbr4103_4

Litman, T. and R. Steele. 2012. Land Use Impact on Transport How Land Use Factors Affect Travel Behavior. Victoria Transport Policy Institute, http://www.vtpi.org/landtravel.pdf.

Lubke, G.H. and B.O. Muthen. 2004. Applying multigroup confirmatory factor models for continuous outcomes to Likert scale data complicates meaningful group comparisons. Structural Equation Modeling 11: 514-534. doi: 10.1207/s15328007sem1104_2

Meng, X. 1994. Posterior predictive p-values. The Annals of Statistics 22(3): 1142-1160.

Mokhtarian, P.L, and X. Cao. 2008. Examining the impacts of residential self-selection on travel be- 
havior: A focus on methodologies. Transportation Research Part B 42: 204-228. doi: 10.1016/j. trb.2007.07.006

Muthén, B. 1984. A general structural equation model with dichotomous, ordered categorical, and continuous latent variable indicators. Psychometrika 49(1): 115-132. doi: 10.1007/BF02294210

Muthén, B. and D. Kaplan. 1985. A comparison of some methodologies for the factor analysis of nonnormal Likert variables. British Journal of Mathematical and Statistical Psychology 38: 171-189. doi: 10.1111/j.2044-8317.1992.tb00975.x.

Naess, P. 2009. Residential self-selection and appropriate control variables in land use: travel studies. Transport Reviews 29(3): 293-324. doi: 10.1080/01441640802710812.

Norman, G. 2010. Likert scales, levels of measuremtne and the "laws"' of statistics. Advances in Health Sciences Education 15(5): 625-632. doi: 10.1007/s10459-010-9222-y.

Pinjari, A. R., R.M. Pendyala, C.R. Bhat, and P.A. Waddell. 2007. Modeling residential sorting effects to understand the impact of the built environment on commute mode choice. Transportation 34(5): 557-573. doi: 10.1007/s11116-007-9127-7.

Salon, D. 2009. Neighborhoods, cars and commuting in New York City: A discrete choice approach. Transportation Research Part A 43: 180-196. doi: 10.1016/j.tra.2008.10.002.

Scheiner, J. and C. Holz-Rau. 2007. Travel mode choice: affected by objective or subjective determinants? Transportation 34: 487-511. doi: 10.1007/s11116-007-9112-1.

Spiegelhalter, D.J., N.G. Best, B.P. Carley, and A. van der Linde. 2002. Bayesian measures of model complexity and fit. Journal of the Royal Statistical Society Series B (Statistical Methodology) 64(4): 583-639. doi: 10.1111/1467-9868.00353.

Schwanen, T. and P.L. Mokhtarian. 2005. What if you live in the wrong neighborhood? The impact of residential neighborhood type dissonance on distance traveled. Transportation Research Part D: Transport and Environment 10(2): 127-151. doi: 10.1016/j.trd.2004.11.002.

Van Acker, V., B. van Wee, and F. Witlox. 2010. When transport geography meets social psychology: toward a conceptual model of travel behaviour. Transport Reviews 30(2): 219-240. doi: $10.1080 / 01441640902943453$.

van Wee, B. 2009. Self-selection: a key to a better understanding of location choices, travel behaviour and transport externalities? Transport Reviews 29(3): 279-292. doi: 10.1080/01441640902752961. 